\title{
Demographic responses of Daphnia magna fed transgenic Bt-maize
}

\author{
Thomas Bøhn $\cdot$ Terje Traavik $\cdot$ Raul Primicerio
}

Accepted: 28 September 2009/Published online: 27 October 2009

(C) The Author(s) 2009. This article is published with open access at Springerlink.com

\begin{abstract}
The food/feed quality of a variety of genetically modified (GM) maize expressing Cry1 Ab Bt-toxin was tested over the life-cycle of Daphnia magna, an arthropod commonly used as model organism in ecotoxicological studies. Demographic responses were compared between animals fed GM or unmodified (UM) near isogenic maize, with and without the addition of predator smell. Agespecific data on survival and birth rates were integrated and analysed using life tables and Leslie matrices. Survival, fecundity and population growth rate (PGR) data generally disfavoured transgenic Bt-maize as feed for D. magna compared to animals fed the unmodified (UM) near isogenic line of maize. Decomposition of age-specific effects revealed that the most important contributions to a reduced PGR in the GM-fed group came from both fecundity and survival differences early in life. We conclude that juvenile and young adult stages are the most sensitive experimental units and should be prioritized in future research. These stages are often omitted in toxicological/ecotoxicological studies and in feeding trials.
\end{abstract}

T. Bøhn $(\bowtie) \cdot$ T. Traavik

Gen $ø$, Center for Biosafety, The Science Park, P.O. Box 6418, 9294 Troms $\varnothing$, Norway

e-mail: thomas@genok.org

R. Primicerio

Department of Arctic and Marine Biology,

University of Tromsø, Troms $\varnothing$, Norway

R. Primicerio

Department of Pharmacy, University of Troms $\varnothing$,

Troms $\varnothing$, Norway
Keywords Age structure - Ecotoxicology · Genetic engineering - Sensitivity ·

Substantial equivalence $\cdot$ Survival

\section{Introduction}

The overall quality of genetically modified (GM) plants, including their nutritional, antinutritional and toxicological properties, has great health and environmental relevance. Industry sources claim a global growth in the production of GM-plants, though concentrated on a handful of countries (James 2006). Thus both trans-boundary movements of GM plants may increase, and more GM material will flux through food chains. Current commercial GM plants have been claimed to be substantially equivalent to unmodified (UM) plants (Brake and Vlachos 1998; Clark and Ipharraguerre 2001; Sidhu et al. 2000). However, the Substantial Equivalence Principle is just a coarse characterisation of the biochemical components of the plant and may overlook important elements like post-translational modifications and immune effects (Prescott et al. 2005), insertional effects leading to up- or down regulation of endogeneous genes (Filipecki and Malepszy 2006), abberations in transgenespecific mRNAs (Rosati et al. 2008), or subtle changes in the proteome and metabolome (Manetti et al. 2006; Zolla et al. 2008).

Few studies have addressed the potential toxicity and health risks of GM plants to animals and humans (Domingo 2007). Feeding studies performed to assess the safety of Bt-maize have mainly focused on adult animals over a relatively short period of their life span (Pryme and Lembcke 2003). However, important effects of toxicants often occur early in life, often due to higher sensitivity of juvenile stages to nutritional inadequacies. Hence, it is 
necessary to focus on juveniles and young adults in both laboratory and field testing (Levin et al. 1996).

Life-cycle experiments cover all life stages of an organism and can thereby detect a broader spectrum of effects on fitness components, being therefore preferable to short-term studies. However, for relatively long lived test organisms like mammals, the costs in resources and time of life-cycle experiments may often be prohibitive. Nevertheless, since GM plants are not expected to be directly toxic or lethal, but may have long-term effects, it is more relevant to perform thorough feeding tests over extensive periods of time, preferably for the whole life-cycle of the animal.

In model organisms with a limited generation time, lifecycle experiments are feasible. The aquatic crustacean Daphnia magna (phylum Arthropoda) has a generation time of about 2 weeks and is commonly used in toxicological and ecotoxicological research (Atienzar et al. 2001; Barry 1996; Kramer et al. 2004). The minimal genetic variation, ensured by its clonal reproduction, as well as easily measurable and plastic life history traits make it an ideal model organism. In short term (48 h) acute toxicity tests, D. magna has shown no treatment-related adverse effects to transgenic Cry1 Ab-maize pollen (Mendelson et al. 2003), but negative, sub-lethal effects were detected by a life cycle feeding test (Bøhn et al. 2008). Life history data collected over the life cycle of test organisms can be further processed to estimate age- or stage-specific survival and fecundity rates. These demographic parameters (i.e. vital rates) are organized in life-tables (Metcalf and Pavard 2007), which make it possible to quantify integrated effects of toxicants on individuals (fitness consequences) and populations (growth rate consequences) (Kammenga and Riksen 1996). It is an explicit goal of ecotoxicology to link physiological effects of contaminants or toxins to their populationand community-level consequences (Moriarty 1988), i.e. ecotoxicological experiments can be analyzed at more than one level of biological organization (Levin et al. 1996). When demographic estimates are based on individual level data, a complete temporal portrait of toxicity (e.g. the age dependent sensitivity) can be obtained, increasing the resolution and scope of toxicological studies (Forbes and Calow 1999).

The link between sub-population level responses and population level consequences can be made using structured population models and Life-Table Response Experiments (LTREs) (Caswell 1989; Caswell 2001). Data generated within LTREs give a complete set of (st)agespecific vital rates (Levin et al. 1996). Thus, it is possible to determine which part of the life-cycle is responsible for an observed population-level response to a treatment. Also, the sensitivity (or elasticity) of each part of the life-cycle is easily obtained from LTRE data (Caswell 2001).

As organisms in the field face multiple challenges or stressors simultaneously, understanding mechanisms of interaction between factors, especially those acting synergistically, is crucial to understand environmental impact (Clarke and Harris 2003; Sih et al. 2004). For example, strong synergistic effects of pesticides and predation on aquatic animals show that two 'safe' effects combined caused 80-90\% of amphibian larvae to die (Relyea 2003; Relyea and Mills 2001). In their most pronounced example of a synergistic effect, the pesticide carbaryl was made 46 times more deadly to bullfrogs in the presence of a predator (Relyea and Mills 2001; Sih et al. 2004). A typical adaptive response to the presence of a predator is to reproduce earlier (i.e. before being eaten) (Stearns 1992). The increased energetic investment in early reproduction has a cost in terms of reduced investment in maintenance, growth and future reproduction expected to amplify the fitness effects of toxic and low nutritional quality food early in life.

Bøhn and co-workers performed a life-cycle experiment with D. magna fed on transgenic Cry1Ab-maize and its near isogenic control, grown in the same environment. They demonstrated increased mortality, reduced growth and a lower number of eggs produced in D. magna feeding on Bt-transgenic maize, likely due to a toxic response to the Bt-maize (Bøhn et al. 2008). In the present study we perform a demographic analysis of those data combined with unpublished data from a predation risk treatment completing the results obtained from our multifactorial design. The demographic analysis allows calculating population growth rate and age-specific responses and sensitivity throughout the life cycle of the test organism. To our knowledge no previous studies have used demographic models to analyse toxicological experiments to test GM foods or feeds.

We tested the following hypotheses:

i) Cry1 Ab-maize is not substantially equivalent to the near isogenic control maize with respect to effects on D. magna health

ii) Juveniles are more sensitive experimental units than adults to potential differences in food or predator treatment

iii) The presence of predator will trigger an allocation trade-off with increased early investment in reproduction at the cost of survival and/or late reproduction that amplifies the response to Cry1Ab-maize

iv) The potential effects of food and predator treatment in combination will act in synergy (as opposed to purely additive effects)

\section{Materials and methods}

Experimental conditions

All individuals of D. magna $(n=80)$ used in the experiments were born within $30 \mathrm{~h}$ from the third clutch of a 
single clonal population. Twenty juvenile individuals were randomly chosen and assigned to separate glasses with $60 \mathrm{ml}$ autoclaved ADAM medium. Ten animals received the GM feed (treatment) and ten the UM feed (control) under identical environmental conditions in a climate chamber at $20^{\circ} \mathrm{C}$ and $24 \mathrm{~h}$ daylight (resembling the summer conditions at our latitude). Every third day, all individuals were transferred to new glasses with new medium using a broad tipped pipette, and the position of the glasses was re-randomized. Each D. magna was fed daily and inspected for survival and number of eggs produced. The experiment lasted for 42 days. Care was taken to provide the same amount of food for all experimental units within and among GM and UM food recipients. Each individual was fed daily with $100 \mu \mathrm{l}$ of maize feed, corresponding to $0.4 \mathrm{mg}$ dry weight of maize or about $0.2 \mathrm{mg} \mathrm{C}$ per individual per day, i.e. within the range recommended for laboratory experiments with Daphnia (Sims et al. 1993). This experimental set-up was performed consecutively three times. In the first of these experiments, parallel experiments were run with and without the additional factor of predator smell, i.e. a $2 \times 2$ fully factorial setup $(n=40$ animals). With the repeated experiments two and three the total number of animals was $n=80$. The present study uses previously published data (Bøhn et al. 2008) combined with unpublished data, i.e. the predator treatment, included in a multifactorial design. The demographic analysis allows calculating population growth rate and agespecific responses and sensitivity throughout the life cycle of the test organism.

\section{Feed}

The transgenic Cry1Ab-maize was of the variety Dekalb 818 YG (a hybrid of MON 810 and a Philippine, local variety of maize called Dekalb 818). Both varieties (Dekalb 818 YG and the near isogenic control maize Dekalb 818) were grown side by side in adjacent fields, divided by a small river, in Elizabeth Cruzara, near Iloilo City in 2003. Maize had been grown on these fields for many years. This was the very first year of GM-maize cultivation. The neighboring farmers delivering the GM and UM-maize have stated that there were no external pesticides used in the fields. We inspected the fields and confirmed their GM and UM status by PCR analyses of field-collected samples before buying the adequate maize material from the local farmer. The transgenic status of the MON810 event was further verified by DNA nucleotide sequencing, employing an Applied Biosystems 3130xl genetic analyzer (data not shown).

On average, the GM-maize expressed 67 ( $\pm 27 \mathrm{SD}) \mathrm{ng}$ $\mathrm{Cry} 1 \mathrm{Ab}$ toxin per gram of dried grain tissue $(n=15$ samples analysed by ELISA, diluted 1:20-1:33, using a commercially available Abraxis kit). All negative controls and the UM-maize showed negative results.
Sub-samples of GM and UM-maize were drawn from $50 \mathrm{~kg}$ bags, and $35 \mathrm{~g}$ of dried kernels were ground with separate coffee-grinders (Petra Espresso), first on the coarsest grinding and then five times repeatedly on the finest setting. The resulting flour was sieved through a filter with $250 \mu \mathrm{m}$ mesh size. $800 \mathrm{mg}$ of the filtered maize flour were added to $250 \mathrm{ml}$ of Aarchnia Daphnien Medium (ADAM) (Kluttgen et al. 1994), homogenized and frozen in $10 \mathrm{ml}$ test tubes. This is later referred to as the feed. All steps of the feed production were the same for GM and UM-maize.

\section{Measurements}

Body length was measured 17, 29 and 42 days after the experiment was initiated. Individual D. magna from both feeding groups were measured for body length (distance from the top of the head to the base of the caudal spine) using a $40 \times$ binocular microscope. While performing the length measurements, the observer did not know to which treatment group the measured individual belonged, to protect from biased measurements.

\section{Predator smell}

The predator smell was produced by feeding three spined sticklebacks Gasterosteus aculeatus with D. magna for 3 days. Stickleback lived in aquarium in the same autoclaved ADAM medium as the daphnids. After feeding on Daphnia spp., fish release 'alarm substances' that trigger predator responses in other daphnids (Brodin et al. 2006; Stabell et al. 2003). Water containing predator smell was filtered and frozen, to obtain ice-cubes of fixed volume $(16 \mathrm{ml})$. The ice cubes containing 'predator smell' were melted and a subsample were added to the medium of the predator smell group, following the protocol of Stabell and colleagues (Stabell et al. 2003).

\section{Demographic analysis}

Age-specific survivorship and fecundity data were obtained for both GM and UM-fed D. magna by daily inspection and egg counts. These data were used to build life-tables and to parameterize the Leslie projection matrix of an age-structured population model (Caswell 2001) using a projection interval of 3 days, i.e. 14 stages covering the 42 days of the experiments (Tables 1 and 2). We included a stage 15 for the animals that were still alive at the end of the experiments. Survival and fecundity for this stage were estimated from stages 12-14.

The Leslie matrices were used to estimate the main demographic statistics for each food treatment, with and without predator. To obtain confidence limits $(95 \% \mathrm{CI})$ for our parameter estimates, we used a bootstrap procedure, 
Table 1 Leslie matrices showing fecundity (first row) and survival (diagonal) for 15 stages of $D$. magna fed on UM (top) or GM (bottom) maize feed. Data from all experiments, with and without predator $(n=80)$

\begin{tabular}{|c|c|c|c|c|c|c|c|c|c|c|c|c|c|c|}
\hline 0 & 0 & 0 & 0 & 0.09 & 0.81 & 0.67 & 0.62 & 0.75 & 0.65 & 0.64 & 0.45 & 0.87 & 0.73 & 0.34 \\
\hline 1.00 & 0 & 0 & 0 & 0 & 0 & 0 & 0 & 0 & 0 & 0 & 0 & 0 & 0 & 0 \\
\hline 0 & 0.97 & 0 & 0 & 0 & 0 & 0 & 0 & 0 & 0 & 0 & 0 & 0 & 0 & 0 \\
\hline 0 & 0 & 0.95 & 0 & 0 & 0 & 0 & 0 & 0 & 0 & 0 & 0 & 0 & 0 & 0 \\
\hline 0 & 0 & 0 & 0.97 & 0 & 0 & 0 & 0 & 0 & 0 & 0 & 0 & 0 & 0 & 0 \\
\hline 0 & 0 & 0 & 0 & 1.00 & 0 & 0 & 0 & 0 & 0 & 0 & 0 & 0 & 0 & 0 \\
\hline 0 & 0 & 0 & 0 & 0 & 0.91 & 0 & 0 & 0 & 0 & 0 & 0 & 0 & 0 & 0 \\
\hline 0 & 0 & 0 & 0 & 0 & 0 & 0.97 & 0 & 0 & 0 & 0 & 0 & 0 & 0 & 0 \\
\hline 0 & 0 & 0 & 0 & 0 & 0 & 0 & 0.87 & 0 & 0 & 0 & 0 & 0 & 0 & 0 \\
\hline 0 & 0 & 0 & 0 & 0 & 0 & 0 & 0 & 0.92 & 0 & 0 & 0 & 0 & 0 & 0 \\
\hline 0 & 0 & 0 & 0 & 0 & 0 & 0 & 0 & 0 & 0.96 & 0 & 0 & 0 & 0 & 0 \\
\hline 0 & 0 & 0 & 0 & 0 & 0 & 0 & 0 & 0 & 0 & 0.96 & 0 & 0 & 0 & 0 \\
\hline 0 & 0 & 0 & 0 & 0 & 0 & 0 & 0 & 0 & 0 & 0 & 0.91 & 0 & 0 & 0 \\
\hline 0 & 0 & 0 & 0 & 0 & 0 & 0 & 0 & 0 & 0 & 0 & 0 & 0.75 & 0 & 0 \\
\hline 0 & 0 & 0 & 0 & 0 & 0 & 0 & 0 & 0 & 0 & 0 & 0 & 0 & 0.73 & 0.79 \\
\hline 0 & 0 & 0 & 0 & 0.10 & 0.45 & 0.67 & 0.48 & 0.74 & 1.06 & 0.40 & 0.92 & 1.43 & 1.00 & 0.56 \\
\hline 0.97 & 0 & 0 & 0 & 0 & 0 & 0 & 0 & 0 & 0 & 0 & 0 & 0 & 0 & 0 \\
\hline 0 & 0.90 & 0 & 0 & 0 & 0 & 0 & 0 & 0 & 0 & 0 & 0 & 0 & 0 & 0 \\
\hline 0 & 0 & 1.00 & 0 & 0 & 0 & 0 & 0 & 0 & 0 & 0 & 0 & 0 & 0 & 0 \\
\hline 0 & 0 & 0 & 0.88 & 0 & 0 & 0 & 0 & 0 & 0 & 0 & 0 & 0 & 0 & 0 \\
\hline 0 & 0 & 0 & 0 & 0.96 & 0 & 0 & 0 & 0 & 0 & 0 & 0 & 0 & 0 & 0 \\
\hline 0 & 0 & 0 & 0 & 0 & 1.00 & 0 & 0 & 0 & 0 & 0 & 0 & 0 & 0 & 0 \\
\hline 0 & 0 & 0 & 0 & 0 & 0 & 0.77 & 0 & 0 & 0 & 0 & 0 & 0 & 0 & 0 \\
\hline 0 & 0 & 0 & 0 & 0 & 0 & 0 & 0.82 & 0 & 0 & 0 & 0 & 0 & 0 & 0 \\
\hline 0 & 0 & 0 & 0 & 0 & 0 & 0 & 0 & 0.86 & 0 & 0 & 0 & 0 & 0 & 0 \\
\hline 0 & 0 & 0 & 0 & 0 & 0 & 0 & 0 & 0 & 0.83 & 0 & 0 & 0 & 0 & 0 \\
\hline 0 & 0 & 0 & 0 & 0 & 0 & 0 & 0 & 0 & 0 & 0.90 & 0 & 0 & 0 & 0 \\
\hline 0 & 0 & 0 & 0 & 0 & 0 & 0 & 0 & 0 & 0 & 0 & 0.89 & 0 & 0 & 0 \\
\hline 0 & 0 & 0 & 0 & 0 & 0 & 0 & 0 & 0 & 0 & 0 & 0 & 0.50 & 0 & 0 \\
\hline 0 & 0 & 0 & 0 & 0 & 0 & 0 & 0 & 0 & 0 & 0 & 0 & 0 & 1.00 & 0.76 \\
\hline
\end{tabular}

performed in Matlab. The procedure re-sampled randomly, with replacement, the individual data, stratifying by treatment group, and calculated the number of eggs, the generation time, the average lifetime reproduction $\left(R_{0}\right)$, and the population growth rate $(\lambda)$ for each of 2000 iterations. The re-sampling was performed so that the proportion of mature animals in each group was constant.

\section{Results}

Survival (1x)

The GM-fed D. magna had lower survival (lx) than the UM-fed D. magna throughout the experiment (Fig. 1). In the 'no predator' group the difference in survival was significant ( $p=0.037$, coxph-test). With predator and for the total material, the differences were not consistent and not statistically significant $(p=0.45$ and $p=0.16$, respectively). For both groups the survival increased somewhat after the main reproductive stages. For the GM-fed groups the killing power (an additive parameter) was about twice as high in comparison to the UM-fed groups in the main reproducing stages (Adult II-VI) (Table 2).

Reproduction (mx)

\section{Egg production}

The total number of eggs produced by GM-fed D. magna was lower than that of those fed UM-maize, 109 versus 141 eggs. The main contributing life stages to egg production 

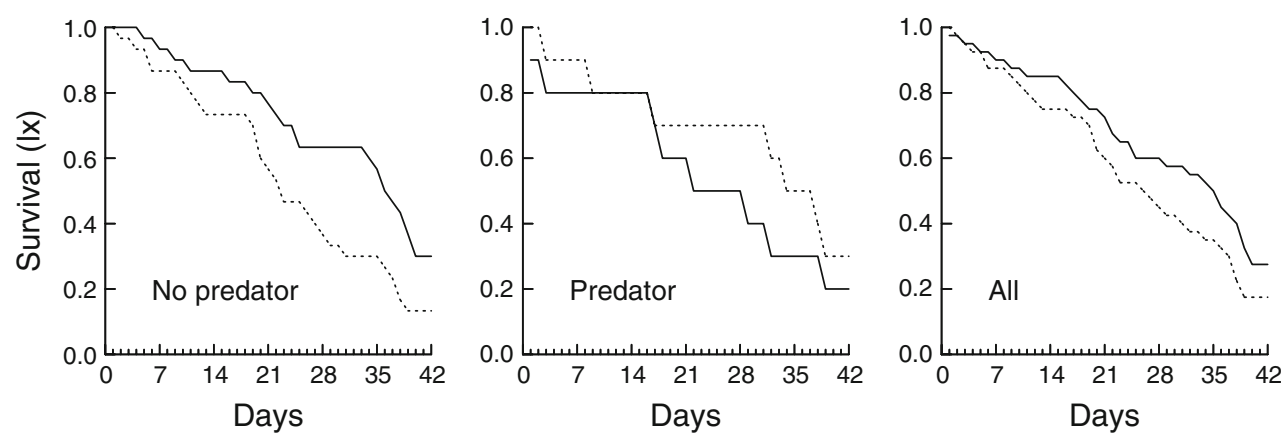

Fig. 1 Survival (lx) for D. magna fed GM-maize (dashed lines) and UM-maize (solid lines), without predator $(n=60)$, with predator $(n=20)$ and all samples combined $(n=80)$

were animals aged 18-30 days in both groups. The number of offspring per surviving individual $(m x)$ was somewhat higher in the UM-fed group in the first reproductive stages, but lower in adults older than 30 days (Fig. 2). The group with predator smell was an exception to this trend as the GM-fed animals consequently had a lower fecundity as compared to the UM-fed animals.

Growth (only with predator)

Daphnia magna fed UM maize were significantly larger in body size at day 29 and 42 as compared to $D$. magna fed GM maize ( $t$-test; $p=0.046$ and $p=0.021$, respectively) (Fig. 3). Without predator a similar but weaker trend was observed (Bøhn et al. 2008).

Demographic parameters and population growth rates

Daphnia magna fed GM maize had consistently lower population growth rates as compared to the control groups fed UM maize, both without (21\% higher) and with predator (87\% higher) present, and thus also for the pooled data (35\% higher) (Fig. 4). With predator and for the total material, the $95 \%$ confidence intervals for the population growth rate did not overlap between the groups (Fig. 4). The inclusion of predator smell stimulated the UM-fed animals, but not the GM fed animals. Age at first reproduction was the same for both groups (13 days) and the generation time was similar (23.9 versus 24.2 days for GM and UM-fed animal, respectively), but the number of eggs and the average lifetime reproduction $\left(R_{0}\right)$ was lower in the GM-fed group as compared to the group fed UM maize $\left(R_{0}=2.73\right.$ and 3.53 , respectively). The bootstrapped confidence intervals did not overlap (Table 3 ).

Decomposition of food treatment effects on agespecific fecundity and survival

The decomposition of fecundity into (st)age-specific effects of food treatment $(n=80)$ showed that the higher fecundity of UM fed D. magna in the earliest adult groups was the dominant contributor to differences in the population growth rate (Fig. 5 upper panels). Conversely, the higher fecundity of GM fed animals in the latest (st)ages had a relatively small contribution to the population growth rate (Fig. 5 upper panels).

For the survival, (st)age-specific effects were more mixed with alternating curves for the two food treatments (Fig. 5 lower panels). However, it is noticeable that after stage 7 (at which the animals were 21 days old) even large absolute differences in survival did not contribute much to the population growth rate (Fig. 5 lower panels).

Decomposition of predator effects on age-specific fecundity and survival

The higher fecundity observed in early stages when the predator was present (Fig. 6, upper left panel) gave the most significant contribution to population growth rate compared to all later differences (Fig. 6, upper right panel).

For the survival, (st)age-specific effects were seemingly asynchronous and mixed between the predator and the nonpredator treatment (Fig. 6, lower left panel). The two main peaks of contribution to population growth rate were early in life with a reduced survival for the predator treatment (Fig. 6, lower right panel).

\section{Discussion}

Daphnia magna fed Bt-transgenic maize showed a reduced fitness performance as compared to animals fed the near isogenic unmodified control maize grown in the same environment. The addition of predator smell increased the differences between the feeding groups, indicating an interaction between food and predator treatment.

Hypothesis 1 Cry1Ab-maize is not substantially equivalent to the near isogenic control maize with respect to effects on D. magna health 


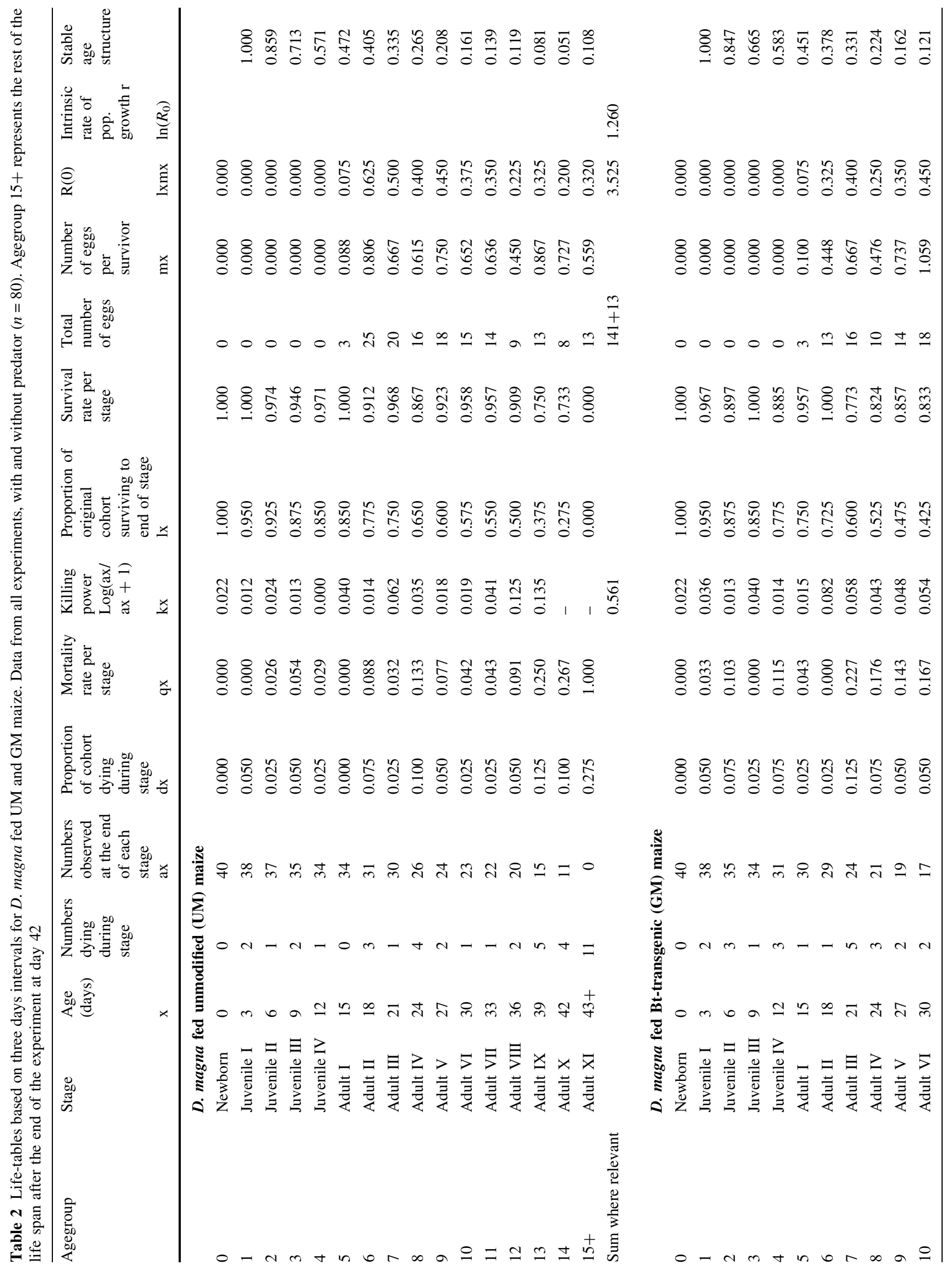




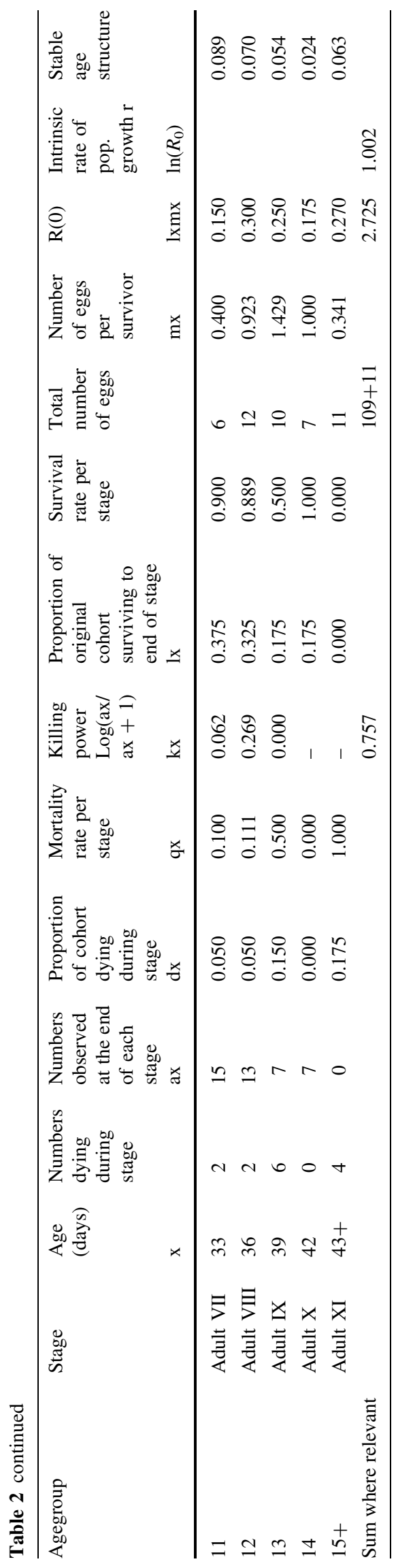

The $\mathrm{H}_{0}$-hypothesis (i.e. Cry1 Ab-maize and near isogenic line are substantially equivalent) was rejected. On a biological level, as food sources for D. magna, the two maize varieties were not performing similarly: (1) the survival of the GM-fed animals were significantly lower than UM-fed, without predator ( $p=0.037$, coxph-test), but not significantly different for the group with predator or for the total material ( $p=0.45$ and $p=0.16$, respectively, coxph-test); (2) the total number of eggs produced by GM-fed animals were lower as compared to animals fed on UM-maize; (3) the growth showed a trend towards larger body sizes in the $\mathrm{UM}$-fed group without predator smell present (Bøhn et al. 2008). When the predator smell was included the UM-fed animals had a significantly larger body size at day 29 and 42 in the experiments; (4) the population growth rate, combining survival and fecundity data, showed a higher growth rate in the UM-fed animals with non-overlapping 95\% confidence intervals for both the predator groups $(n=20)$ and for the total material $(n=80)$. These results sum up differences in repeated and fully randomized lifecycle experiments, using maize as the only source of food.

The most common definition of substantial equivalence has emphasized the biochemical components of the plant (Brake and Vlachos 1998; Clark and Ipharraguerre 2001; Sidhu et al. 2000), thus potentially overlooking important elements like post-translational modifications and immune effects (Prescott et al. 2005), insertional effects leading to up- or down regulation of endogeneous genes (Filipecki and Malepszy 2006), abberations in transgene-specific mRNAs (Rosati et al. 2008), or subtle changes in the proteome and metabolome (Manetti et al. 2006; Zolla et al. 2008). Animal feeding studies are performed to reveal subtler effects on survival, growth, histological indicators, and other characteristics of consumers. This means that effects can be picked up even without a clear understanding of the cause(s), e.g. the mode of action for a toxin.

Our data demonstrate negative effects in the non-target organism D. magna feeding insecticide maize, but we lack the mechanistic explanation for the effect. A number of other studies, mainly in terrestrial invertebrates, have also showed negative effects of Bt-transgenic plants on nontarget species. Lövei and Arpaia (2005) found significantly negative effects on about $30 \%$ of the studied invertebrate predators and $57 \%$ of the studied parasitoids after feeding Bt-plants or pollen. Hilbeck and Schmidt (2006) report 27 out of 54 studies $(50 \%)$ that showed negative effects after feeding Bt-plants or pollen. Ramirez-Romero and co-workers showed a tri-trophic effect where a parasitoid hymenopteran species was negatively affected (developmental time, adult size and fecundity) via host exposure to Cry $1 \mathrm{Ab}$ proteins and Bt-plants (Ramirez-Romero et al. 2007). The same group also showed that honey bees were negatively affected in their feeding behaviour and that their 
Fig. 2 Fecundity $(m x)$ for D. magna fed GM-maize (dashed lines) and UM-maize (solid lines), without predator $(n=60)$, with predator $(n=20)$ and all samples combined $(n=80)$
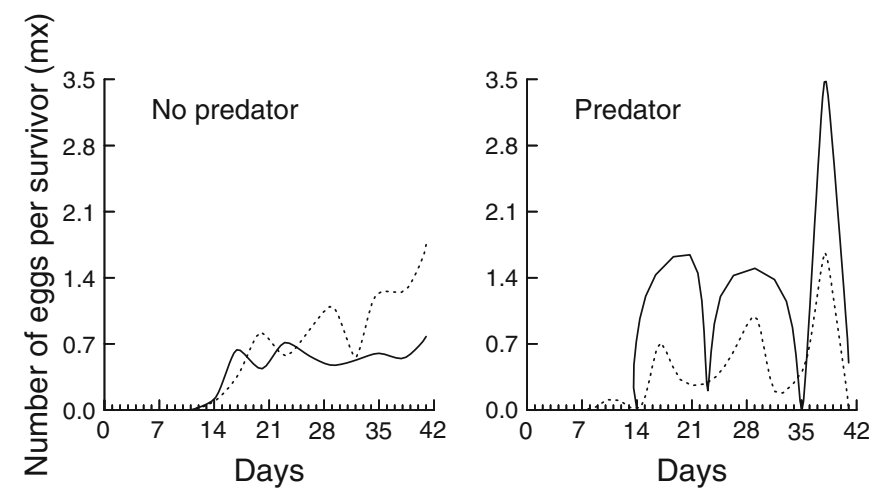

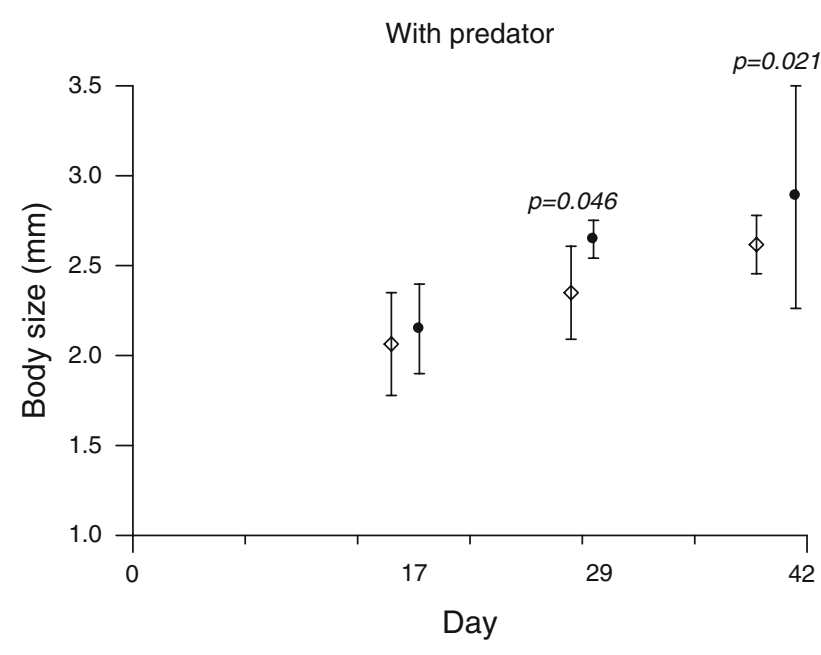

Fig. 3 Mean body size (whiskers, 95\% CI) of D. magna fed on GM-maize (open squares) and UM-maize (filled circles) at days 17, 29 and 42. The $p$-values of significant differences are shown ( $t$-test)

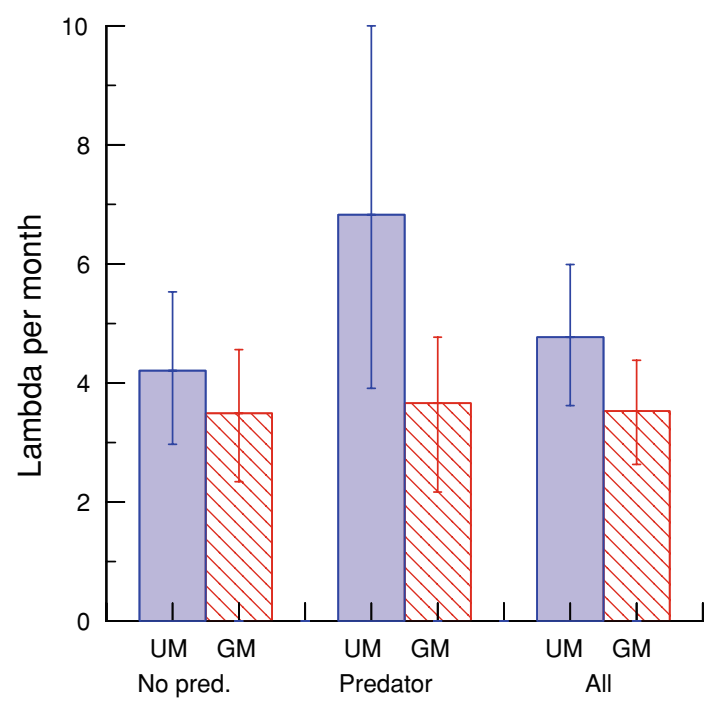

Fig. 4 Population growth rate per month (lambda-whiskers, 95\% bootstrap CI) for D. magna fed unmodified (UM) and modified (GM) maize, without predator $(n=60)$, with predator $(n=20)$ and for all samples combined $(n=80)$
Table 3 Demographic data on D. magna fed GM and UM maize

\begin{tabular}{lll}
\hline Stage-classified model & GM-fed & UM-fed \\
\hline No. of females in experiments & 40 & 40 \\
Age at first reproduction (days) & 13 & 13 \\
Number of eggs & 109 & 141 \\
Upper 95\% confidence interval & 134 & 175 \\
Lower 95\% confidence interval & 82 & 109 \\
Average lifetime reproduction $\left(R_{0}\right)$ & 2.73 & 3.53 \\
Upper 95\% confidence interval & 3.35 & 4.37 \\
Lower 95\% confidence interval & 2.05 & 2.73 \\
Generation time & 23.9 & 24.2 \\
Upper 95\% confidence interval & 24.6 & 24.7 \\
Lower 95\% confidence interval & 22.3 & 23.3 \\
\hline
\end{tabular}

Confidence intervals are calculated from bootstrapping. Data from all experiments, with and without predator $(n=80)$

learning performance was reduced when exposed to $5,000 \mathrm{ppb}$ of Cry1Ab protein (Ramirez-Romero et al. 2008). Moser and co-workers showed that the developmental time of $C$. maculata increased after Bt hybrid corn treatments compared with non-Bt corn treatments (Moser et al. 2008). In the aquatic environment, it has been demonstrated that toxin-containing crop byproducts from maize are dispersed, decomposed and consumed by stream insects (Rosi-Marshall et al. 2007). When fed Bt-maize in the laboratory, two non-target caddisflies showed higher mortality and reduced growth (Rosi-Marshall et al. 2007).

None of the mentioned studies were able to identify the cause(s) of the effect(s), e.g. the mode of action for the Bt-toxins. This leaves us with a knowledge gap and an urgent need for more detailed studies focusing on mechanism. New methodological techniques like functional genomics, transcriptomics, proteomics, metabolomics, etc. may prove helpful in order to improve the understanding about both the properties of the plant, and the properties of the test organism that feed on that plant. This will immediately bring the discussion well beyond the coarse assumptions made by the substantial equivalence principle. 
Fig. 5 (Top): decomposition of food treatment (dashed line $=\mathrm{GM}$, solid line $=\mathrm{UM})$ effects on the (st)age-specific fecundity for the total material $(n=80)$. Left panel shows absolute effects (relative to the mean) and right panel shows the contributions of those effects on the population growth rate. (Bottom): decomposition of food treatment effects on the (st)age-specific survival. Left panel shows absolute effects (relative to the mean) and right panel shows the contributions of those effects on the population growth rate
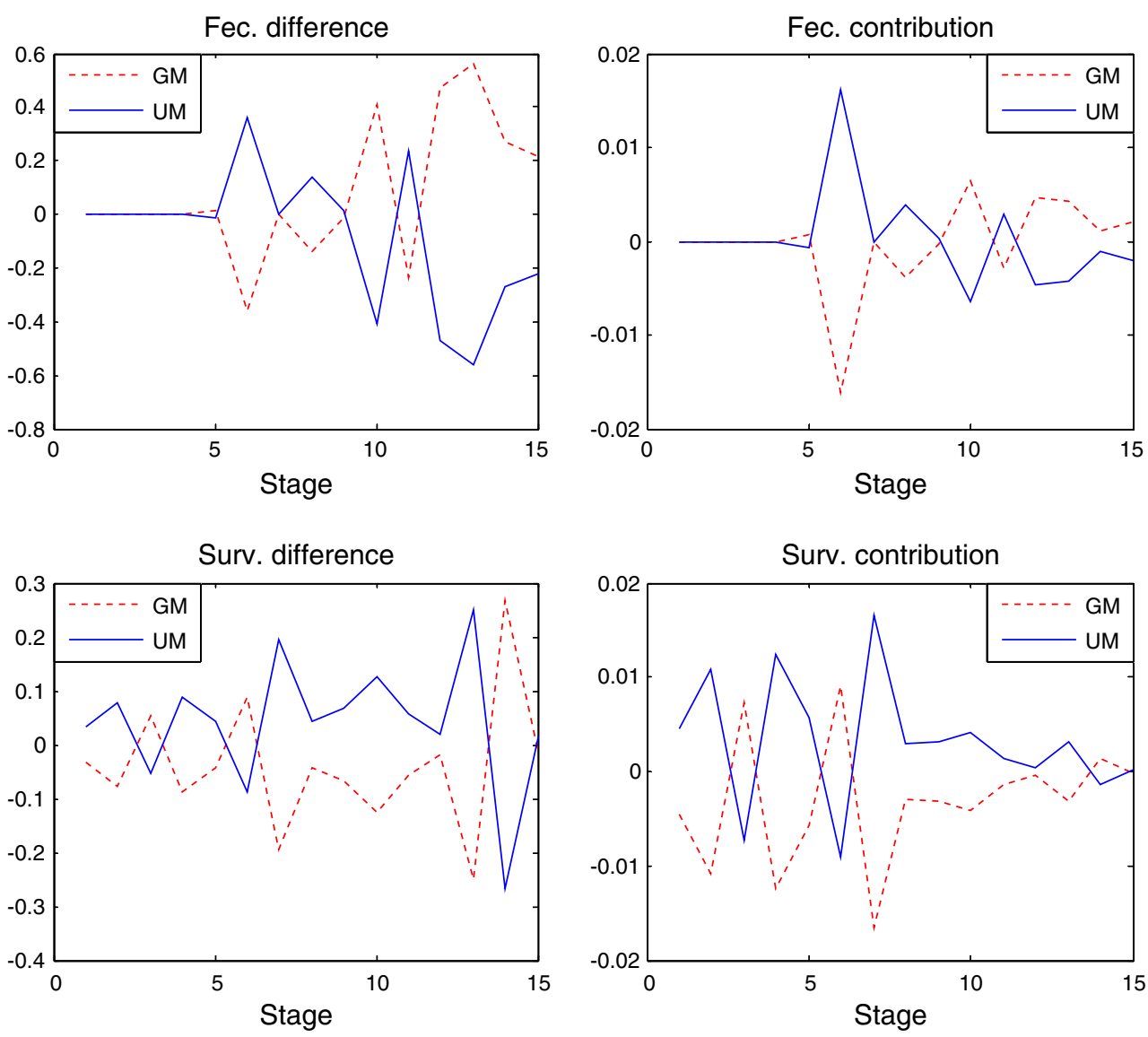

One promising research direction is ecotoxicogenomics where gene expression patterns are studied under the impact of different treatments, e.g. exposure to chemicals. Watanabe and co-workers showed that chemicals expected to impact oxidative stress, respiratory uncoupling, metabolic change and heavy metal exposure altered gene expression patterns in D. magna in recognizable ways (Watanabe 2007). Also, DNA microarrays for D. magna have been used to link gene responses to the impact of toxicants on life-history traits and population growth rate in D. magna (Connon et al. 2008). If, or when further studies are able to link a negatively affected phenotype after exposure to e.g. Bt-toxin, or after feeding on a transgenic plant, to up- or down-regulation of certain genes or pathways, a new and promising step towards finding modes of action would have been established. However, a functional genomics determinism, i.e. tightly relating changes in microarrays, changes in proteins and changes in the metabolome is far from established. Assuming such determinism could narrow our investigations and understanding of the phenotype.

In spite of the abovementioned, the basis for analysis of risks from transgenic plants still largely remains that of substantial equivalence. Following Millstone and co-workers that called the Substantial Equivalence Principle a regulatory principle without any biological relationship or theoretical validity (Millstone et al. 1999), we argue that the concept of substantial equivalence should have a definition based on its biological activity. It is the biological activity that is relevant in the agro-ecosystem, in relation to nontarget effects and in a human health context. Otherwise, there would be no necessary link between substantial equivalence and safety.

Hypothesis 2 Juveniles are more sensitive experimental units than adults to potential differences in food or predator treatment

Hypothesis supported. Given the differences in the performance of $D$. magna fed GM versus UM maize and the detailed demographic analysis, we were able to evaluate which stages of the D. magna life cycle were the most sensitive to differences in food quality, and to predator smell. The survival curves of both feeding groups were relatively straight and the fecundity tended to increase with age. However, the sensitivity analysis revealed that what really mattered to the population growth rate came from differences in survival in juveniles and young adults and from fecundity differences in young adults. Thus, the structured population models offer results on sensitivity which may have important implications: juveniles and 
Fig. 6 (Top): effects of predator treatment (dashed line $=$ predator, solid line $=$ no predator) on (st)age-specific fecundity (left) and the contributions of those effects on population growth rate (right). (Bottom): effects of predator on (st)age-specific survival (left) and the contributions of those effects on population growth rate (right)
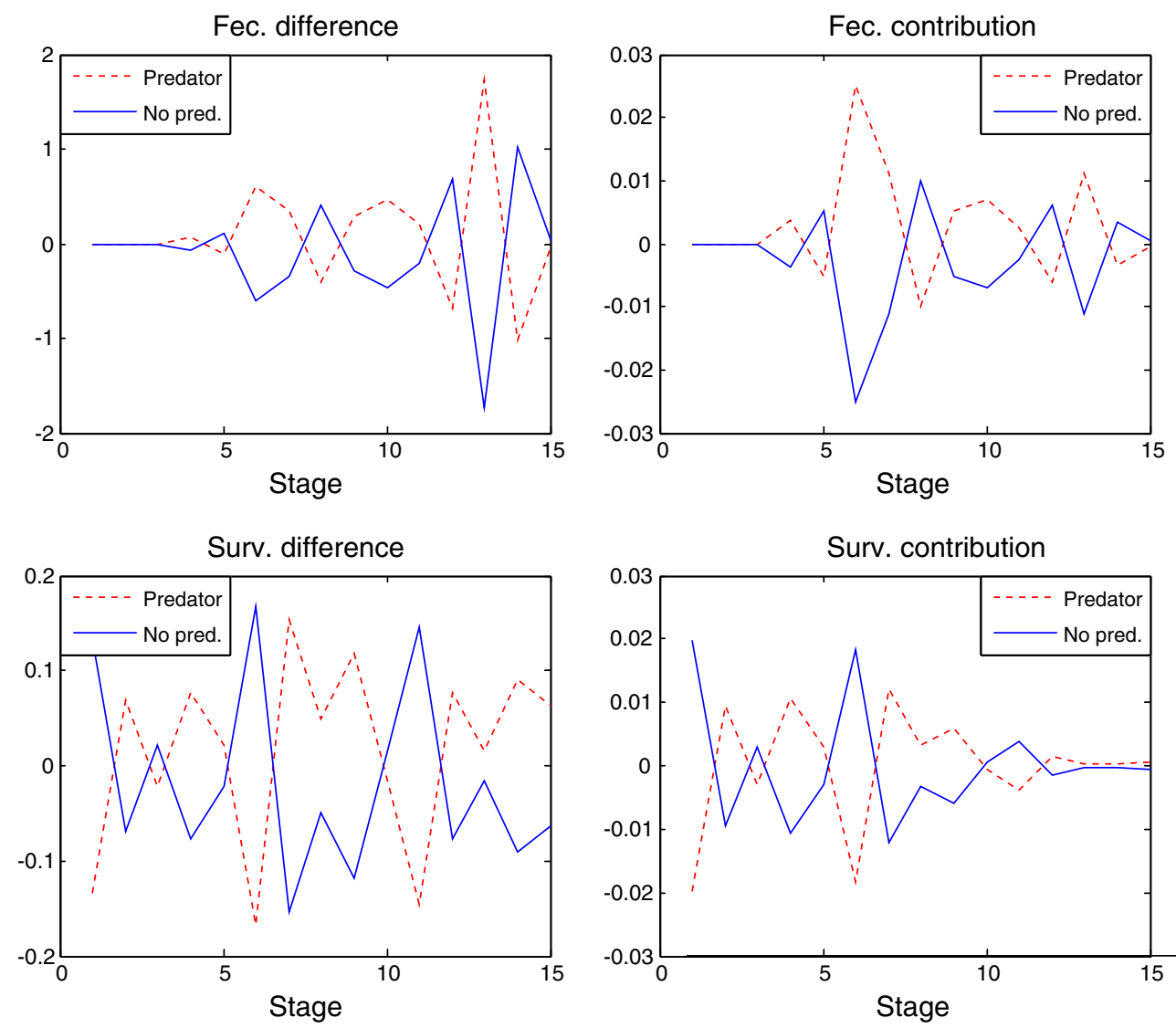

young adult stages are the most sensitive experimental units and should be prioritized in toxicological/ecotoxicological research (Connon et al. 2008; Forbes and Calow 1999). This is often contrary to established practice, where well fed adults are used for testing. For example, Cry1Ab pollen is tested in adult D. magna, short term with no treatment related effects found (Mendelson et al. 2003). In short-lived test organisms, we recommend the use of life cycle experiments to enable stage specific evaluation of toxicity and general life-history performance, including population level comparisons. When applicable, these methods are superior to traditional testing practices.

Hypothesis 3 The presence of predator will trigger an allocation trade-off with increased early investment in reproduction at the cost of survival and/or late reproduction that amplifies the response to Cry1 Ab-maize

Hypothesis partly supported. A trade-off response was observed in animals exposed to predator, but only in the UM-fed animals. This group increased their population growth rate by increasing their early reproduction as anticipated by life-history theory (Hansen et al. 1999; Mauri et al. 2003; Twombly et al. 1998). However, the early boost in reproduction coincided with a relatively high mortality, indicating a cost of the response. When a predator is present, the expectation of a shorter life span may trigger early reproduction (Sakwinska and Dawidowicz 2005). Also other stress factors than predation may lead to high fecundity early in life (Coors et al. 2004) at the cost of future quantity or quality of offspring, e.g. due to a compromised immune system (Hanssen et al. 2005; Sheldon and Verhulst 1996). In general, a negative correlation between current and residual reproductive value, or between other life-histoty traits, has been used to show the cost of reproduction (Harshman and Zera 2007; Stearns 1992).

Interestingly, the GM-fed animals showed no apparent response in fecundity to the presence of the predator cue. We argue that the lack of the anticipated response and the relatively low reproductive output for this group was caused by a reduced health condition after feeding the Bt-transgenic maize. The appropriate life-history response may simple require a reasonably good health condition. The lack of response by early reproduction may, however, explain the somewhat higher survival in the animals fed Bt-transgenic maize and exposed to predator, compared to the early reproducing animals that were fed unmodified maize and exposed to predator. 
Looking at the population level, the predator smell stimulated a higher population growth rate for the group fed UM-maize, which may seem paradoxical since a predator usually represents a stress factor that reduces growth and delays reproduction (Auld and Relyea 2008; Brodin et al. 2006). However, as the experiments did not last long enough to detect possible counteracting responses towards the end of life, i.e. a reduced reproductive output after the end of the experiment (day 42), the expected trade-off between early and late reproduction could not be evaluated completely. Also, the predator smell may have contributed with a small portion of nutrients, e.g. bacteria, to the sterile ADAM medium, thereby stimulating the test animals.

Hypothesis 4 The potential effects of food and predator treatment in combination will act in synergy (as opposed to purely additive effects)

Hypothesis supported. The differences between the GM-fed and UM-fed animals were larger in the presence of a predator: the population growth rate was markedly reduced in animals exposed to both GM maize and predator as compared to animals exposed to UM maize and predator. Also, the differences in body size for GM and UM-fed animals were much clearer in the groups with predator treatment, c.f. (Bøhn et al. 2008). Thus, the results indicate that the effects of food treatment and predator treatment were not additive, but interacted. As argued above, we emphasize that an organism under stress from two factors may be unable to respond adequately to several stressing conditions in the environment.

In conclusion, this study shows negative effects of a Bt-transgenic maize variety on a non-target model organism. The study thus rejects the substantial equivalence of the tested GM and UM-maize. Extended analysis using structured population models combine effects on survival and reproduction and enabled us to compare effects both on the population level, and on the sensitivity of different agegroups within food and predator treatments. Life-cycle experiments analysed with structured population models should be used, when applicable, to derive better estimates of the impact of novel food stuff, pesticides, toxicants and other stressors. Such demographic studies offer complete time-series portraits of toxicity and represents an improvement over traditional toxicological data and analysis. We urge more research on altered phenotypes and life-histories due to exposure from transgenic plants, ideally in combination with detailed-omics techniques, to follow the missing link of the specific causes and mechanisms involved in observed negative effects.

Acknowledgments We would like to thank farmers from the Iloilo district, Chito Medina and MASIPAG, the Philippines, for providing the maize samples used in the experiments. We are grateful to
Professor Kaare M. Nielsen for valuable discussions about the experiments. We also thank Dr. Idun Grønsberg, Marte Albrigtsen, Julia Eggert, and Elisabeth Olsen at the GenØk Lab in Tromsø, and to Dr. Morten Johansen and Kriss Rokkan Iversen at the Norwegian College of Fishery Science for practical assistance during the experiments. John Pope improved greatly the understanding of matrix calculations and Gill Pope provided the best environment possible for a decisive modelling workshop in Suffolk, august 2007. The study was supported by a grant (project no. 154504) from the Research Council of Norway.

Open Access This article is distributed under the terms of the Creative Commons Attribution Noncommercial License which permits any noncommercial use, distribution, and reproduction in any medium, provided the original author(s) and source are credited.

\section{References}

Atienzar FA, Cheung VV, Vadesh NJ, Epledge MH (2001) Fitness parameters and DNA effects are sensitive indicators of copperinduced toxicity in Daphnia magna. Toxicol Sci 59:241-250

Auld JR, Relyea RA (2008) Are there interactive effects of mate availability and predation risk on life history and defence in a simultaneous hermaphrodite? J Evol Biol 21:1371-1378

Barry MJ (1996) Effects of an organochlorine pesticide on different levels of biological organization in Daphnia. Ecotoxicol Environ Saf 34:239-251

Bøhn T, Primicerio R, Hessen DO, Traavik T (2008) Reduced fitness of Daphnia magna fed a Bt-transgenic maize variety. Arch Environ Contam Toxicol 55:584-592

Brake J, Vlachos D (1998) Evaluation of transgenic event 176 "Bt" corn in broiler chickens. Poult Sci 77:648-653

Brodin T, Mikolajewski DJ, Johansson F (2006) Behavioural and life history effects of predator diet cues during ontogeny in damselfly larvae. Oecologia 148:162-169

Caswell H (1989) The analysis of life table response experiments. I. decomposition of of treatment effects on population growth rate. Ecol Modell 46:221-236

Caswell H (2001) Matrix population models: construction, analysis, and interpretations, 2nd edn. Sinauer Assosiates, Inc. Publishers, Sunderland

Clark JH, Ipharraguerre IR (2001) Biotech crops as feeds for livestock. Abstr Pap Am Chem Soc 222:U67

Clarke A, Harris CM (2003) Polar marine ecosystems: major threats and future change. Environ Conserv 30:1-25

Connon R, Hooper HL, Sibly RM, Lim FL, Heckmann LH, Moore DJ, Watanabe H, Soetaert A, Cook K, Maund SJ, Hutchinson TH, Moggs J, De Coen W, Iguchi T, Callaghan A (2008) Linking molecular and population stress responses in Daphnia magna exposed to cadmium. Environ Sci Technol 42:2181-2188

Coors A, Hammers-Wirtz M, Ratte HT (2004) Adaptation to environmental stress in Daphnia magna simultaneously exposed to a xenobiotic. Chemosphere 56:395-404

Domingo JL (2007) Toxicity studies of genetically modified plants: a review of the published literature. Crit Rev Food Sci 47:721-733

Filipecki M, Malepszy S (2006) Unintended consequences of plant transformation: a molecular insight. J Appl Genet 47:277-286

Forbes VE, Calow P (1999) Is the per capita rate of increase a good measure of population-level effects in ecotoxicology? Environ Toxicol Chem 18:1544-1556

Hansen FT, Forbes VE, Forbes TL (1999) Effects of 4-n-nonylphenol on life-history traits and population dynamics of a polychaete. Ecol Appl 9:482-495 
Hanssen SA, Hasselquist D, Folstad I, Erikstad KE (2005) Cost of reproduction in a long-lived bird: incubation effort reduces immune function and future reproduction. Proc R Soc Lond B Biol Sci 272:1039-1046

Harshman LG, Zera AJ (2007) The cost of reproduction: the devil in the details. Trends Ecol Evol 22:80-86

Hilbeck A, Schmidt JEU (2006) Another view on Bt proteins-how specific are they and what else might they do? Biopestic Int 2:1-50

James C (2006) Global status of commercialized biotech/GM crops: 2006. ISAAA, Ithaca

Kammenga JE, Riksen JAG (1996) Comparing differences in species sensitivity to toxicants: phenotypic plasticity versus concentrationresponse relationships. Environ Toxicol Chem 15:1649-1653

Kluttgen B, Dulmer U, Engels M, Ratte HT (1994) Adam, an artificial fresh-water for the culture of zooplankton. Water Res 28:743-746

Kramer KJM, Jak RG, van Hattum B, Hooftman RN, Zwolsman JJG (2004) Copper toxicity in relation to surface water-dissolved organic matter: biological effects to Daphnia magna. Environ Toxicol Chem 23:2971-2980

Levin L, Caswell H, Bridges T, DiBacco C, Cabrera D, Plaia G (1996) Demographic responses of estuarine polychaetes to pollutants: life table response experiments. Ecol Appl 6:1295-1313

Lövei GL, Arpaia S (2005) The impact of transgenic plants on natural enemies: a critical review of laboratory studies. Entomologia Experimentalis et Applicata 114:1-14

Manetti C, Bianchetti C, Casciani L, Castro C, Di Cocco ME, Miccheli A, Motto M, Conti F (2006) A metabonomic study of transgenic maize (Zea mays) seeds revealed variations in osmolytes and branched amino acids. J Exp Bot 57:2613-2625

Mauri M, Baraldi E, Simonini R (2003) Effects of zinc exposure on the polychaete Dinophilus gyrociliatus: a life-table response experiment. Aquat Toxicol 65:93-100

Mendelson M, Kough J, Vaituzis Z, Matthews K (2003) Are Bt crops safe? Nat Biotechnol 21:1003-1009

Metcalf CJE, Pavard S (2007) Why evolutionary biologists should be demographers. Trends Ecol Evol 22:205-212

Millstone E, Brunner E, Mayer S (1999) Beyond 'substantial equivalence'. Nature 401:525-526

Moriarty G (1988) Ecotoxicology: the study of pollutants in ecosystems, academic. San Diego, California

Moser SE, Harwood JD, Obrycki JJ (2008) Larval feeding on Bt hybrid and non-Bt corn seedlings by Harmonia axyridis (Coleoptera : Coccinellidae) and Coleomegilla maculata (Coleoptera : Coccinellidae). Environ Entomol 37:525-533

Prescott VE, Campbell PM, Moore A, Mattes J, Rothenberg ME, Foster PS, Higgins TJV, Hogan SP (2005) Transgenic expression of bean alpha-amylase inhibitor in peas results in altered structure and immunogenicity. J Agric Food Chem 53:9023-9030

Pryme IF, Lembcke R (2003) In vivo studies on possible health consequences of genetically modified food and feed-with particular regard to ingredients consisting of genetically modified plant materials. Nutr Health 17:1-8
Ramirez-Romero R, Bernal JS, Chaufaux J, Kaiser L (2007) Impact assessment of Bt-maize on a moth parasitoid, Cotesia marginiventris (Hymenoptera: Braconidae), via host exposure to purified Cry1 Ab protein or Bt-plants. Crop Prot 26:953-962

Ramirez-Romero R, Desneux N, Decourtye A, Chaffiol A, PhamDelegue MH (2008) Does CrylAb protein affect learning performances of the honey bee Apis mellifera L. (Hymenoptera, Apidae)? Ecotoxicol Environ Saf 70:327-333

Relyea RA (2003) Predator cues and pesticides: a double dose of danger for amphibians. Ecol Appl 13:1515-1521

Relyea RA, Mills N (2001) Predator-induced stress makes the pesticide carbaryl more deadly to gray treefrog tadpoles (Hyla versicolor). Proc Natl Acad Sci USA 98:2491-2496

Rosati A, Bogani P, Santarlasci A, Buiatti M (2008) Characterisation of $3^{\prime}$ transgene insertion site and derived mRNAs in MON810 YieldGard $^{\circledR}$ maize. Plant Mol Biol. doi: 10.1007/s11103-0089315-7

Rosi-Marshall EJ, Tank JL, Royer TV, Whiles MR, Evans-White M, Chambers C, Griffiths NA, Pokelsek J, Stephen ML (2007) Toxins in transgenic crop byproducts may affect headwater stream ecosystems. Proc Natl Acad Sci USA 104:16204-16208

Sakwinska O, Dawidowicz P (2005) Life history strategy and depth selection behavior as alternative antipredator defenses among natural Daphnia hyalina populations. Limnol Oceanogr 50:12841289

Sheldon BC, Verhulst S (1996) Ecological immunology: costly parasite defences and trade-offs in evolutionary ecology. Trends Ecol Evol 11:317-321

Sidhu RS, Hammond BG, Fuchs RL, Mutz JN, Holden LR, George B, Olson T (2000) Glyphosate-tolerant corn: the composition and feeding value of grain from glyphosate-tolerant corn is equivalent to that of conventional corn (Zea mays L.). J Agric Food Chem 48:2305-2312

Sih A, Bell AM, Kerby JL (2004) Two stressors are far deadlier than one. Trends Ecol Evol 19:274-276

Sims IR, Watson S, Holmes D (1993) Toward a standard Daphnia juvenile production test. Environ Toxicol Chem 12:2053-2058

Stabell OB, Ogbebo F, Primicerio R (2003) Inducible defences in Daphnia depend on latent alarm signals from conspecific prey activated in predators. Chem Senses 28:141-153

Stearns SC (1992) The evolution of life histories. Oxford University Press, Oxford

Twombly S, Clancy N, Burns CW (1998) Life history consequences of food quality in the freshwater copepod Boeckella triarticulata. Ecology 79:1711-1724

Watanabe H (2007) Toxicogenomics as a tool for evaluation of chemical effects. Yakugaku Zasshi-J Pharm Soc Jpn 127:19671974

Zolla L, Rinalducci S, Antonioli P, Righetti PG (2008) Proteomics as a complementary tool for identifying unintended side effects occurring in transgenic maize seeds as a result of genetic modifications. J Proteome Res 7:1850-1861 